\title{
Recommendations for Oil Extraction and Refining Process to Prevent the Formation of Monochloropropane-diol Esters in Sunflower Oil
}

\author{
Karine Redeuil*, Xanthippe Theurillat, Marine Nicolas, Kornél Nagy \\ Société des Produits Nestlé S.A-, Nestlé Research Lausanne, Route du Jorat 57, 1000 Lausanne 26, Switzerland
}

* To whom correspondence should be addressed:

Karine Meisser Redeuil, Société de Produits Nestlé SA, Nestlé Research Lausanne, EPFL Innovation Park, Building H, CH-1015 Lausanne

Email: karine.meisser@rdls.nestle.com

Phone: + 41217859229 
Table S1: Phosphatidylcholine levels at various stages of the refining process of a solvent extracted cake oil

\begin{tabular}{ccccccc}
\hline Type of Oil & dipalmitoyl-PC & $\begin{array}{c}\text { palmitoyl-oleoyl- } \\
\text { PC }\end{array}$ & dioleoyl-PC & $\begin{array}{c}\text { palmitoyl- } \\
\text { linoleoyl-PC } \\
\text { (PA ratio) }\end{array}$ & $\begin{array}{c}\text { oleoyl-linoleoyl- } \\
\text { PC }\end{array}$ & dilinoleoyl-PC \\
\hline SE cake oil & 0.07 & 2.31 & 13.32 & 6.25 & 7.21 & 17.95 \\
Deg. SE cake oil & 0.00 & 0.00 & 0.02 & 0.00 & 0.01 & 0.01 \\
1-week cooling SE cake oil & 0.03 & 1.23 & 7.15 & 3.37 & 4.07 & 10.34 \\
1-week cooling Deg. SE cake oil & 0.00 & 0.00 & 0.07 & 0.03 & 0.04 & 0.08 \\
\hline
\end{tabular}




\section{SUPPLEMENTAL FIGURE CAPTIONS}

Figure S1: Relative abundance of reported discovered chlorine carrying substances (see Table 1, ion $[\mathrm{M}-\mathrm{H}]^{-}$) and levels of sunflower major MCPD diesters formed during the in-vitro heat treatment of crude sunflower oil.

Figure S2: Distribution of chlorine-carrying substances identified in negative ionization mode (A) in various bio sunflower oil fractions.

(peak areas were all normalized to OLL peak area)

Figure S3: Distribution of major MCPDEs (LL, OL, PL, OO) in various bio sunflower oil fractions.

(peak areas were all normalized to their deuterated ISTD peak area)

Figure S4: Relative distribution of chlorine carriers class A (A); class B (B); class C (C) and class D (D) along the sunflower refining process. The sum of each carrier class was taken into account and normalized to their internal standard nicarbazin.

Process step identity: A (Crude); B (Degummed); C (Degummed short cooling); D (Degummed short cooling bleached); E (Degummed bleached short cooling); F (Degummed bleached)

Figure S5: Total 2-MCPD (A) and glycidol content (B) along the sunflower refining process.

Process step identity: A (Crude); B (Degummed); C (Degummed short cooling); D (Degummed short cooling bleached); E (Degummed bleached short cooling); F (Degummed bleached) 


\section{SUPPLEMENTAL FIGURES}

Figure S1

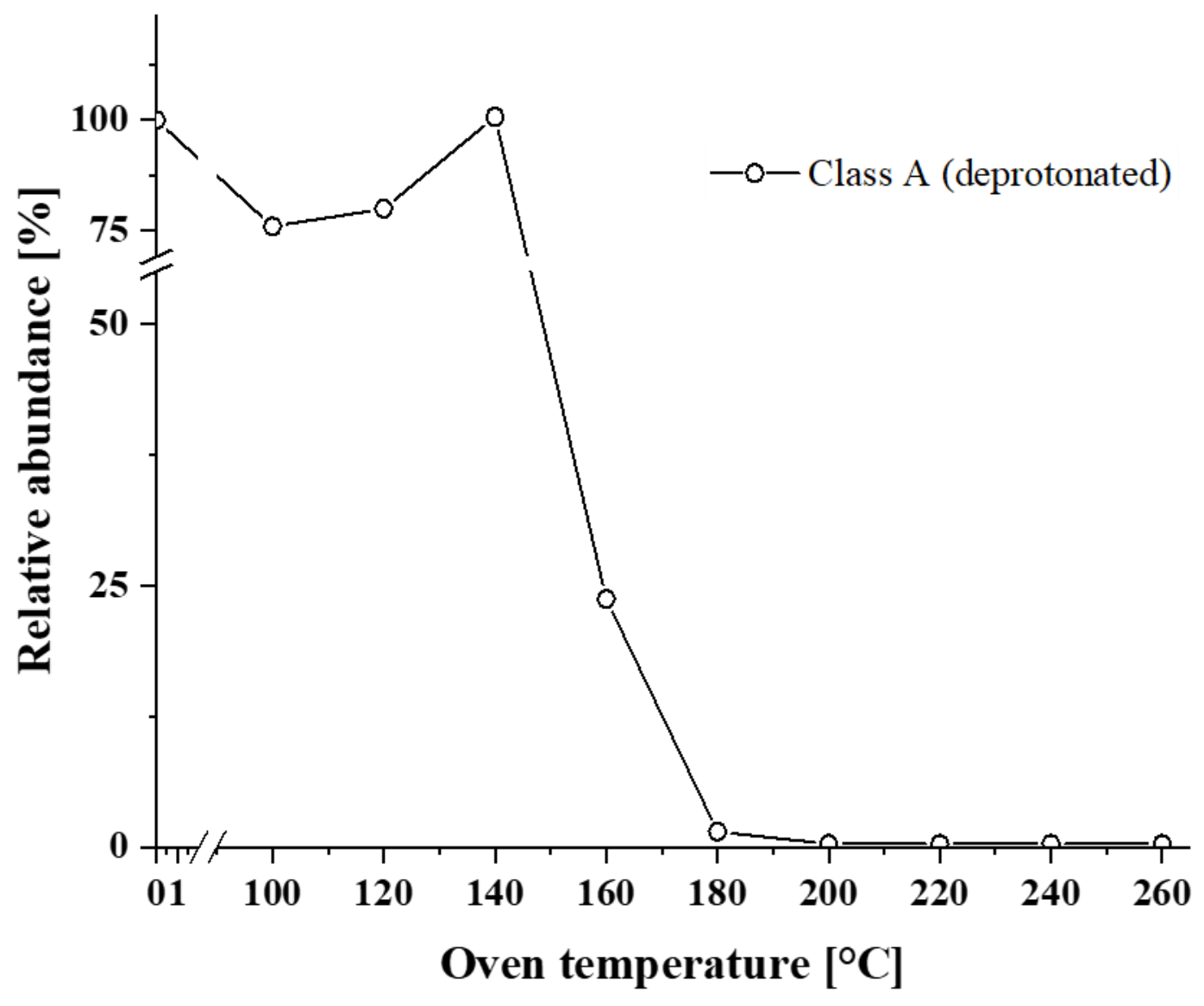


Figure S2

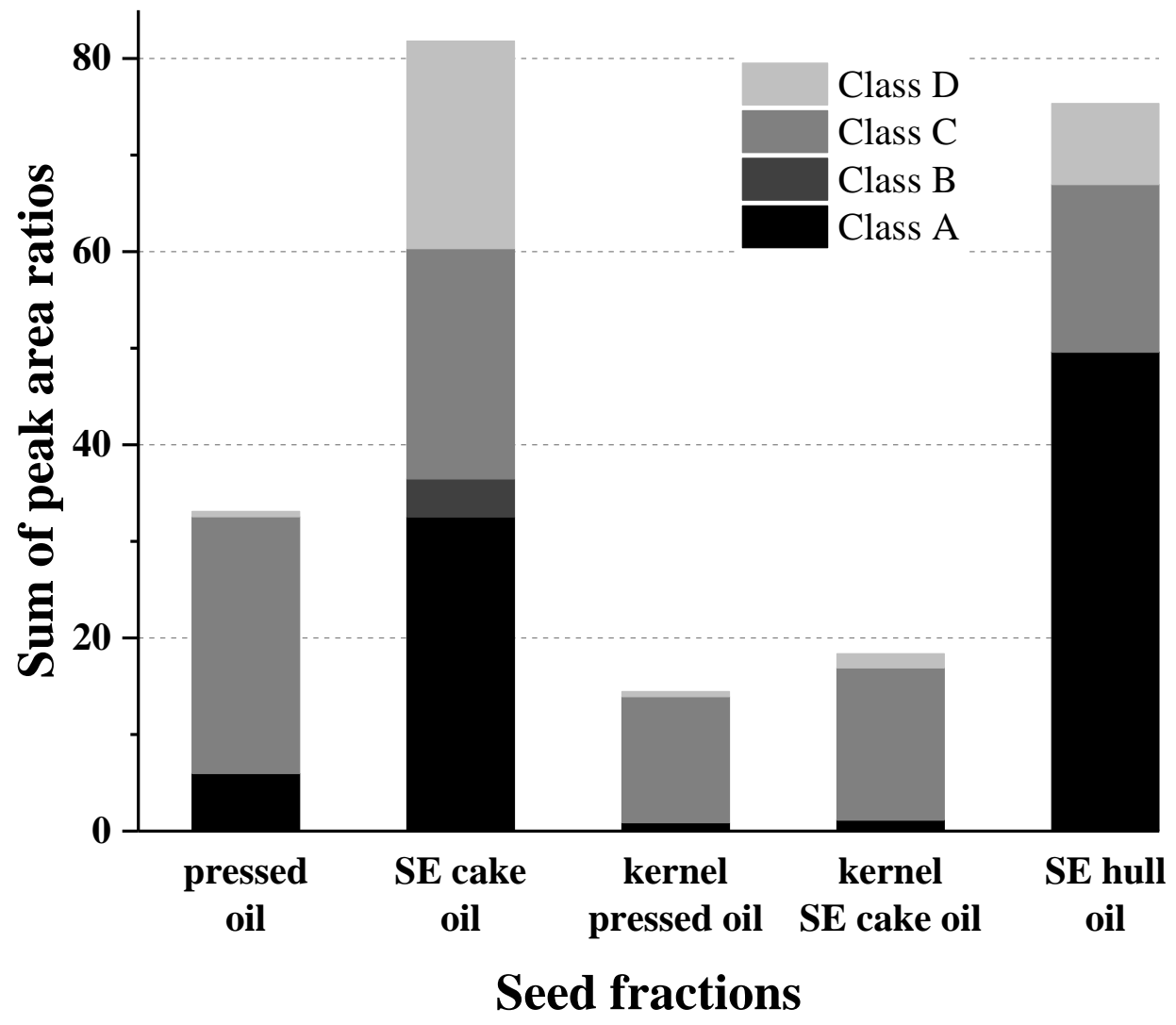


Figure S3

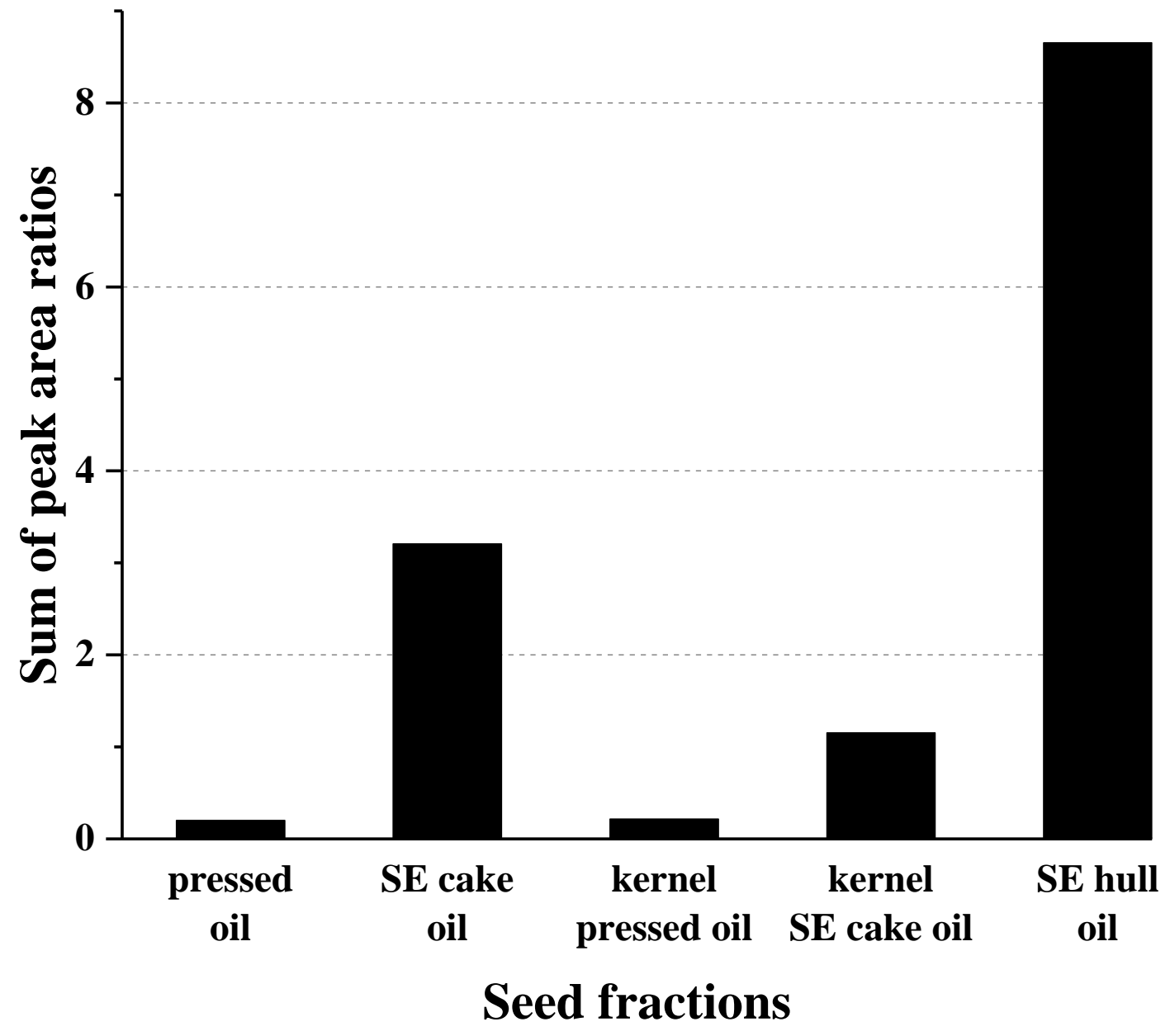


Figure S4
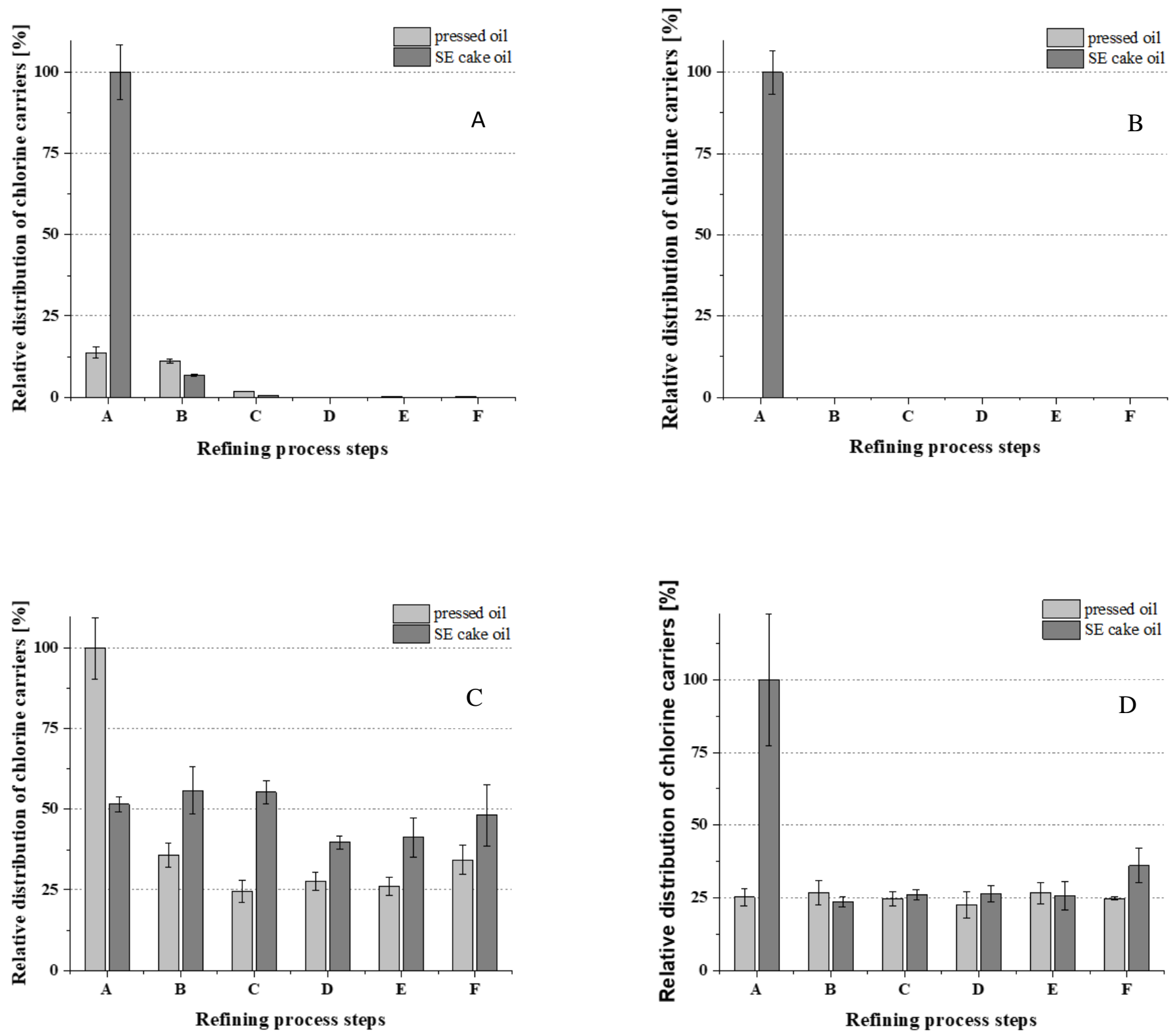
Figure S5
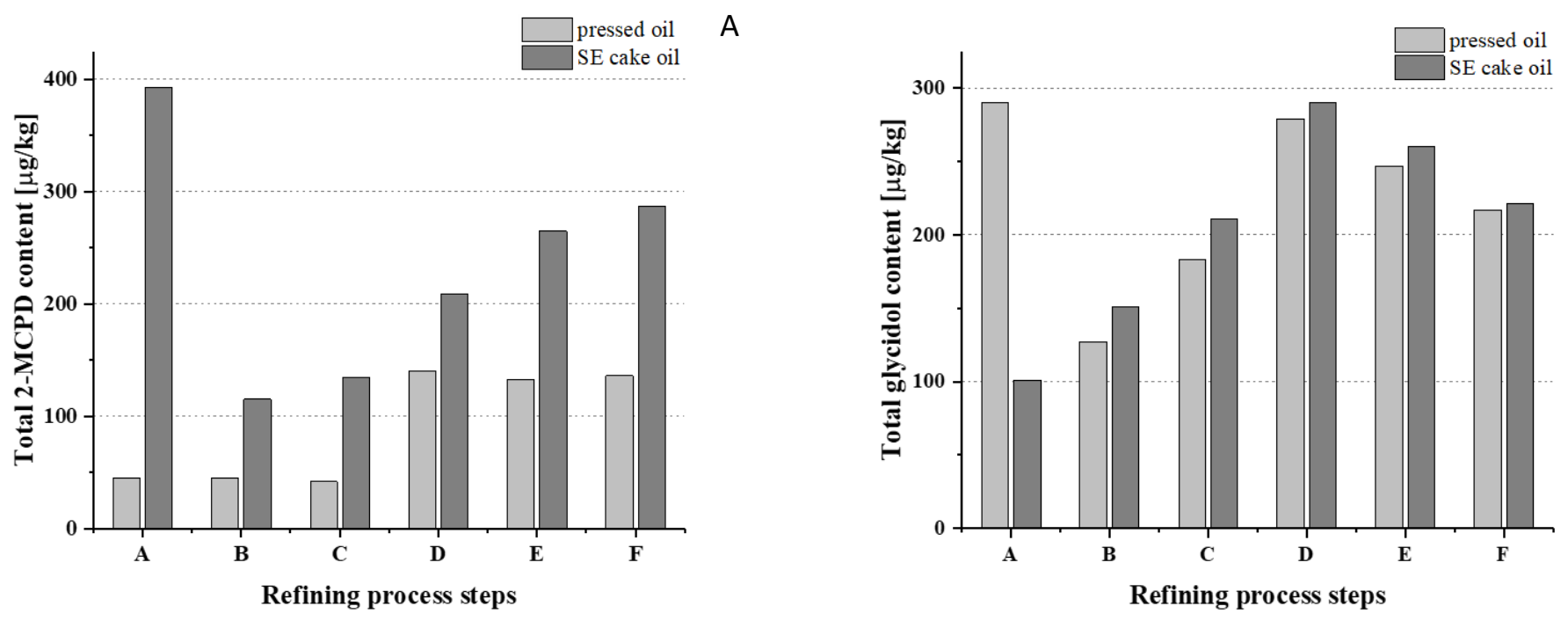

B 